\title{
A percepção de professoras cursistas do Parfor sobre as contribuições do Parfor à prática pedagógica
}

\author{
Paulo Pedro Schuetzitio \\ Universidade Regional do Cariri, Crato, CE, Brasil \\ Gabriel Vitor Acioly Gomesii@ \\ Universidade São Francisco, Campinas, SP, Brasil \\ Lucila Moraes Cardoso iii \\ Universidade Estadual do Ceará, Fortaleza, CE, Brasil
}

\begin{abstract}
Resumo
O Plano Nacional de Formação de Professores da Educação Básica visa oferecer aos professores acesso ao ensino superior gratuito e de qualidade. Objetivou-se analisar a percepção de professoras cursistas de Pedagogia do referido plano na região do Cariri, interior do Ceará, sobre a sua ação docente à luz da epistemologia da prática. Um docente do Plano Nacional de Formação de Professores da Educação Básica solicitou que as professoras cursistas do plano respondessem a um questionário com perguntas sobre a formação delas para a docência. O questionário foi respondido por 13 docentes e posteriormente houve reflexões durante as aulas. A partir de uma análise qualitativa do material, os resultados sugeriram distância entre a formação inicial e as demandas de sala de aula e diferentes motivações para o ingresso na docência. Concluiu-se que é preciso discutir sobre as realidades profissionais e sociais para que ocorra aproximação com a epistemologia da prática.
\end{abstract}

\section{Palavras-chave}

Formação de professores. Qualificação para o magistério. Docência.

\section{The perception of student-teachers about Parfor's contributions to pedagogical practice}

\begin{abstract}
The National Plan for the Training of Basic Education Teachers aims to offer teachers access to free and quality university education. The objective of this study was to analyze the perception of Pedagogy course teachers of the referred plan in the Cariri region, inland Ceará, about their teaching action in the light of the epistemology of practice. A teacher from the National Plan for the Training of Basic Education Teachers asked the student-teachers to answer a questionnaire with questions about their training for teaching. The questionnaire was answered by 13 teachers and subsequently there were reflections during classes. From a qualitative analysis of the material, the results suggested a distance between the initial training and classroom demands and different motivations for entering teaching. It was concluded that it is necessary to discuss about professional and social realities so that there is an approximation with the epistemology of practice.
\end{abstract}

\section{Keywords}

Teacher Education. Qualification for Teaching. Teaching.

Educ. Form., Fortaleza, v. 6, n. 3, e4646, set./dez. 2021

DOI: https://doi.org/10.25053/redufor.v6i2.4646

https://revistas.uece.br/index.php/redufor/index 


\title{
La percepción de las estudiantes-profesoras sobre las contribuciones
} del Parfor a la práctica pedagógica

\begin{abstract}
Resumen
El Plan Nacional de Formación del Profesorado de Educación Básica tiene como objetivo ofrecer a los profesores acceso a una educación universitaria gratuita y de calidad. El objetivo de este estudio fue analizar la percepción de las profesoras del curso de Pedagogía del referido plan en la región de Cariri, interior de Ceará, sobre su acción docente a la luz de la epistemología de la práctica. Un docente del Plan Nacional de Formación del Profesorado de Educación Básica solicitó a las estudiantes-profesoras que respondieran a un cuestionario con preguntas sobre su formación para la docencia. El cuestionario fue respondido por 13 profesoras y posteriormente hubo reflexiones durante las clases. A partir de un análisis cualitativo del material, los resultados sugirieron una distancia entre la formación inicial y las demandas del aula y diferentes motivaciones para ingresar a la docencia. Se concluyó que es necesario discutir sobre las realidades profesionales y sociales para que exista una aproximación con la epistemología de la práctica.
\end{abstract}

\section{Palabras clave}

Formación de profesores. Calificación para la enseñanza. Docencia.

\section{Introdução}

Ao abordar sobre a formação de professoras ${ }^{1}$ é importante demarcar que a docência diz respeito a uma prática profissional situada, complexa e socialmente produzida e que as professoras são pessoas ativas que ressignificam e intervêm no cotidiano de sua prática (OLIVEIRA; ARAÚJO; DA SILVA, 2021). Essa formação constitui-se como processo articulado entre a ação e a reflexão, voltando à ação qualificada (LIBÂNEO, 2006). A melhoria da formação de professoras perpassa por reflexões que valorizam a prática como exercício de problematização e reconhecimento que resultam na produção de saber que lhes favorecem suporte para soluções nas suas práticas (LIMA; ANDRADE; COSTA, 2020; MEZZAROBA; CARRIQUIRIBORDE, 2020; PIMENTA, 2006).

Entende-se a epistemologia da prática quando a professora elabora conhecimento que é "[...] produzido na ação e sobre a ação de ensinar" (LIMA; GOMES, 2006, p. 164). A categoria da professora reflexiva insere-se neste ideário pedagógico, isto é, uma docente que mobiliza uma teoria sobre sua prática implica indissociabilidade

1 Neste artigo, optou-se por se referir às professoras adotando o gênero feminino, no sentido de demarcar que essa profissão, no Brasil, é majoritariamente composta por mulheres.

Educ. Form., Fortaleza, v. 6, n. 3, e4646, set./dez. 2021

DOI: https://doi.org/10.25053/redufor.v6i2.4646

https://revistas.uece.br/index.php/redufor/index 
com postura reflexiva. Como afirmou Tardif (2002), é por meio de autonomia, reflexão e discernimento acerca dos saberes cotidianos que se constituem objetos epistêmicos docentes, assim falar da professora reflexiva vai além de pensar sobre o "quê" e o "como" fazer, que poderia ser o cerne do planejamento de qualquer professora sem maiores preocupações com mudanças e transformações externas ao seu processo. Trata-se de uma postura crítica visando às transformações desde o objeto de análise, da prática, como também visando à qualificação dos resultados reverberados na realidade contextual mais ampla a partir do pensar e refletir (LIBÂNEO, 2006), nutridos por teoria da educação (PIMENTA, 2006). Logo, a professora reflexiva e a epistemologia da prática são categorias de análise imbricadas.

No Brasil, a expansão do acesso à escola para todos ocorreu por meio de legislação que promoveu o direito e a obrigatoriedade da educação, sendo elas as Leis no 4.024/1961 e no 5.692/1971, que foram revogadas pela Lei o 9.394/1996. Concomitante a essa expansão, a falta de investimento na educação e na qualificação docente fez com que professoras fossem para sala de aula sem que tivessem uma formação adequada e, por vezes, interesse nessa atuação (SILVA; CORRÊA, 2020; SOUSA; MARQUES, 2019).

Com a proposição de suprir lacunas na formação docente, o governo federal publicou o Decreto oㅜ 6.755/2009, que gerou o Plano Nacional de Formação dos Professores da Educação Básica (Parfor). O Parfor é considerado uma política emergencial que incentiva a formação em nível superior de professoras que atuam na educação básica pública, proporcionando-Ihes chances de acesso à Educação Superior gratuita e de qualidade (CARVALHO, 2020). Assim, os princípios que devem orientar as Instituições de Educação Superior (IES) no planejamento pedagógico tratam da:

[...] articulação entre teoria e prática em todo o percurso formativo; garantia do domínio de conhecimentos científicos e didáticos; indissociabilidade entre ensino, pesquisa e extensão e reconhecimento da escola como espaço necessário à formação inicial dos profissionais do magistério. (BRASIL, 2013, p. 28).

Tendo em vista o objetivo do Parfor, entende-se que ele é um mecanismo de suma importância para a qualificação docente, pois por meio da formação é possível que as professoras compartilhem conhecimentos e vivências e, a partir de reflexões sobre as práticas, construam novas possibilidades de atuação (DUARTE, 2019). O Parfor torna-se 
ainda mais relevante ao compreender que visa alcançar um público, geralmente, afastado dos grandes centros urbanos, com dificuldade de ser atendido por políticas públicas e que sofre pela desigualdade social, bem como enfrenta entraves administrativos no âmbito da prefeitura e escola, como salientado por Santos (2018).

Considerando a importância social e científica de compreender os contextos formativos de professores, há um interesse nas experiências em que se permite a autorreflexão por parte das professoras sobre as contradições existentes nas práticas pedagógicas. Dessa forma, objetivou-se neste trabalho fazer uma análise da percepção de professoras cursistas de Pedagogia do Parfor da Universidade Regional do Cariri (Urca) convidadas para refletir na e sobre a sua ação docente à luz da epistemologia da prática.

Além desta Introdução, o artigo está organizado em quatro seções. Na primeira, é abordado o Parfor como um programa de formação de professoras; na segunda, é relatada a experiência que viabilizou obter a percepção das participantes do estudo; na terceira, são tecidas algumas análises a partir da percepção de professoras cursistas do Parfor; e, por último, há considerações gerais sobre os resultados desta pesquisa.

\section{Política Nacional de Formação dos Profissionais da Educação Básica (Parfor)}

O Decreto n 6.755/2009 regulamentou a Política Nacional de Formação de Profissionais do Magistério da Educação Básica, inovando ao tratar a formação de professoras, seja inicial ou continuada, como um compromisso público (SANTOS, 2018). Meses depois, foi publicada a Portaria Normativa $n^{\circ}$ 9, de 30 de junho de 2009, que instituiu o Parfor no âmbito do Ministério da Educação (MEC), sendo revogada pelo Decreto no 8.752/2016, mantendo a consonância com o Plano Nacional de Educação (PNE) aprovado em 2014. Em seu artigo 3ํ, alínea I, o Parfor foi incorporado como um dos objetivos da Política Nacional de Formação dos Profissionais da Educação Básica, instruindo que este "[...] deverá articular ações das instituições de ensino superior vinculadas aos sistemas federal, estaduais e distrital de educação, por meio da colaboração entre o Ministério da Educação, os Estados, o Distrito Federal e os Municípios".

A partir da regulamentação do Parfor, o censo escolar passou a explicitar o quantitativo de profissionais que necessitavam de formação inicial em nível superior, 
bem como de professoras que já tinham uma formação de ensino superior, mas que necessitavam de formação continuada (SANTOS, 2018). O acesso ao Parfor ocorre por meio de turmas especiais ofertadas por IES para as professoras que atendam a um dos critérios estabelecidos:

\begin{abstract}
a) primeira licenciatura - para docentes em exercício na rede pública da educação básica que não tenham formação superior; b) segunda licenciatura para docentes em exercício há pelo menos três anos na rede pública que atuem em área distinta da sua formação inicial; e c) formação pedagógica - para docentes graduados, mas não licenciados. (BRASIL, 2013).
\end{abstract}

No ano de criação do Parfor, matricularam-se 4.273 professoras, distribuídas em 140 turmas. Após cinco anos, contava com 70.220 matrículas em 2.145 turmas especiais ofertadas por 96 IES (BRASIL, 2013). Dez anos após a sua criação, havia um total de 100.408 matriculados em 3.043 turmas implantadas por 104 IES (BRASIL, 2021). Nota-se, desse modo, que o número de professoras que aderiram à formação proposta pelo Parfor é expressivo. O índice de evasão no Parfor segue tendência observada nas graduações regulares, em torno de $16,53 \%$, e se relaciona, praticamente, à falta de apoio às professoras em formação. A maioria dessas professoras utiliza seu tempo livre (férias, feriados e finais de semana) para participar do curso e precisa viajar para os locais onde as atividades acadêmicas são realizadas (BRASIL, 2013).

As turmas especiais são ofertadas por cursos de licenciatura credenciados no Sistema de Regulação do Ensino Superior/e-MEC e, se tiverem sido avaliados pelo Instituto Nacional de Estudos e Pesquisas Educacionais Anísio Teixeira (Inep), devem ter o conceito igual ou superior a 3 (BRASIL, 2013). O Projeto Pedagógico do Curso (PPC) corresponde ao das graduações regulares e o principal diferencial seria o fato de as turmas especiais serem compostas exclusivamente por cursistas que comprovem estar exercendo a docência na rede pública.

Para Rodrigues et al. (2018), é fundamental que os docentes do Parfor levem em consideração essa especificidade das turmas especiais. Os autores questionam se deveria ter um PPC diferenciado, visando ampliar o estímulo para que sejam adotadas estratégias pedagógicas que possibilitem integrar a experiência de sala de aula das docentes cursistas do Parfor. A possibilidade de incluir nessa formação as experiências das docentes cursistas possibilitaria reflexões pertinentes sobre a sala de aula, a relação 
com os alunos e os desafios presentes no cotidiano educacional (SCHUETZ, 2018). Essa perspectiva se ampara também nas críticas amplamente debatidas por Imbernón (2009), ao considerar a discrepância que há entre a experiência formativa e a realidade escolar.

O fato de o Parfor representar um avanço à formação docente no Brasil não o isenta de críticas. Na Carta de Teresina - Parfor, documento apresentado no I Encontro Norte e Nordeste do Parfor em 2013, citado por Mota (2015), foram indicados como entraves que assegurassem uma formação devidamente qualificada: a falta de financiamento para a aquisição de materiais permanentes e equipamentos; o não pagamento de bolsa para os estudantes participarem de atividades de ensino, pesquisa e extensão; a defasagem no valor da bolsa destinada aos coordenadores do programa; a falta de compromisso de estados e municípios quanto à obrigatoriedade e à valoração das contrapartidas; a inexistência de ações efetivas para enfrentar as assimetrias regionais; a carência de oportunidades para produção, publicação e divulgação de produção acadêmica; e a infraestrutura deficitária, faltando bibliotecas, laboratórios de informática, entre outros.

Pode-se dizer que o Parfor é uma proposta pertinente, mas os resultados ainda deixam a desejar no tocante à efetividade para mudanças, transformações e inovações (SCHUETZ, 2018). Nesse sentido, retoma-se a crítica feita por Santos (2018) de que o Parfor foi institucionalizado como um programa, e não uma política de Estado, permitindo que possa sofrer perda de recursos progressivos, a depender do governante.

Considerando esse programa no contexto do Cariri cearense, Araújo et al. (2012) avaliaram de que forma o Parfor contribui à formação dos professores da educação básica na Urca. A pesquisa contou com entrevistas estruturadas e filmagens de docentes cursistas e professores do curso de Pedagogia do Parfor. Dentre as problemáticas enfrentadas, tem-se o fato de que parte dos cursos funciona em escolas da rede pública de ensino fundamental e médio dos municípios, cujos espaços na maioria possuem uma estrutura física inadequada à proposta, uma vez que as salas são pequenas, com carteiras projetadas para crianças ou adolescentes, e os banheiros inadequados. Além de ventilação escassa, faltam livros, biblioteca, laboratórios e equipamentos para orientar a condução de pesquisas. Igualmente preocupante é o perfil das professoras cursistas do Parfor, que relatam sobrecarga de tarefas e responsabilidades e que consideram a avaliação como uma estratégia de julgamento e 
opressão. Mesmo com esses problemas, as participantes reforçaram que o Parfor contribui positivamente para a formação delas.

Em outro estudo, Mota (2015) analisou como a área de ação do currículo do curso de Pedagogia do Parfor da Urca influencia na prática docente dos alunos que já exercem a docência. Para tal, considerou como potenciais participantes 34 professoras cursistas, os docentes e o coordenador do curso de Pedagogia do Parfor da Urca no período de 2013 e 2014. Ao final do trabalho, verificou que a titulação é importante para a vida particular, para sentir-se valorizado profissionalmente perante os colegas e para reafirmar as práticas já desenvolvidas nas suas atividades docentes em salas de aula que precisavam de uma base teórica para fundamentá-las.

Por fim, Rodrigues et al. (2018) analisaram a experiência da primeira turma do Parfor na Urca, refletindo sobre a formação inicial em serviço, a constituição da docência e as interferências e inferências na prática pedagógica por meio das narrativas das professoras cursistas do Parfor. As participantes valorizaram o contato com bons professores e relataram a precariedade do espaço físico para o funcionamento das aulas e a sobrecarga de tarefas, considerando o acúmulo das atividades profissionais concomitantes à formação. No que se refere às motivações para serem docentes, 0 discurso ancorou-se na ideia de que a motivação foi iniciada na infância, perpassou pela adolescência, até ser concretizada na vida adulta. Na maioria dos casos, a formação inicial que as possibilitou atuar foi amparada por terem cursado o $2^{\circ}$ grau de magistério ${ }^{2}$. Ao falarem sobre a motivação para o Parfor, elencaram um desejo anterior de cursar licenciatura em Pedagogia com a exigência de diploma em nível superior para que pudessem se manter no emprego. As autoras concluíram que, aparentemente, a formação do Parfor ainda está arraigada numa posição governamental de ofertar a proposta sem dar ênfase às condições necessárias para a permanência e o aproveitamento do curso.

\section{Método}

Este trabalho foi fruto de uma experiência em sala de aula do primeiro autor, docente do Parfor, tratando-se de um estudo qualitativo de pesquisa-ação. A pesquisa

2 Referência à formação de professores primários, que se inaugura com a Habilitação Específica para o Magistério de $2^{\circ}$ grau a partir da Lei ํㅜ 5.692/1971.

Educ. Form., Fortaleza, v. 6, n. 3, e4646, set./dez. 2021

DOI: https://doi.org/10.25053/redufor.v6i2.4646

https://revistas.uece.br/index.php/redufor/index ISSN: 2448-3583 
foi realizada com professoras cursistas de Pedagogia do Parfor da Urca. Todas as professoras eram residentes e docentes nos municípios de Juazeiro do Norte, Crato, Barbalha, Missão Velha e Caririaçu na Região Metropolitana do Cariri do Ceará, situada a 600 quilômetros das capitais, Fortaleza (Ceará) e Recife (Pernambuco). Foram tomados os devidos cuidados para inviabilizar a identificação dos participantes, assegurando a recomendação do inciso VII da Resolução do Conselho Nacional de Saúde ํㅜ 510/2016, que permite que sejam realizadas pesquisas sem a submissão ao sistema da Comissão Nacional de Ética em Pesquisa (Conep), quando "[...] objetiva o aprofundamento teórico de situações que emergem espontânea e contingencialmente na prática profissional, desde que não revelem dados que possam identificar o sujeito" (BRASIL, 2016b).

As professoras cursistas do Parfor que participaram das atividades pertencem ao quadro de funcionárias de cinco diferentes municípios de áreas rurais no interior do Ceará, sendo a maioria com idade entre 25 e 35 anos, casadas, com filhos, atuando na docência havia aproximadamente cinco anos, contratadas em regime temporário. Elas relataram que não usufruem de direitos trabalhistas nem de férias remuneradas e dependem da vontade política de cada novo mandatário para permanecerem no programa.

Os encontros foram realizados em dois polos no interior do estado do Ceará, com cinco momentos de dez horas cada. Os encontros aconteceram na sexta-feira, das 18 horas às 21 horas, e no sábado, das 8 horas às 16 horas, e ocorreram nos municípios sede do Parfor, de modo que o deslocamento das professoras foi assegurado pelo poder público dos municípios onde lecionavam.

Em um dos encontros, o docente do Parfor entregou às professoras cursistas um questionário com cinco perguntas, pediu-lhes que o levassem para casa e 0 respondessem se quisessem, devolvendo-Ihe o questionário na aula seguinte. Das 43 professoras, 13 entregaram o material preenchido. As perguntas do questionário eram: “1) Escreva sobre a sua formação para ser professora antes de entrar no Parfor"; "2) Escreva sobre os motivos que Ihe levaram a ser professora"; "3) O Parfor está contribuindo com a sua formação? De que forma as aulas do Parfor mudaram a sua atuação em sala de aula? Explique um pouco"; "4) Destaque pontos positivos e negativos sobre a formação do Parfor"; e "5) Gostaria de fazer outras observações, 
indicações ou sugestões?". As respostas objetivaram analisar a experiência docente à luz das possibilidades reflexivas sobre a formação e o trabalho escolar.

As respostas foram digitadas no computador, depois foi preparado o corpus textual das questões para que, por fim, fossem feitas as análises pelo software Interface de R pour les Analyses Multidimensionnelles de Textes et de Questionnaires (Iramuteq). Esse software é livre e gratuito e é utilizado para realizar processamento estatístico de dados lexicais/textuais, ou seja, tem como unidade de análise o vocabulário. Neste trabalho foram adotados dois tipos de análises: 1) nuvem de palavras, que se caracteriza por fazer uma organização gráfica de acordo com a frequência de palavras existentes no corpus textual; e 2) análise de similitude, que leva em consideração a associação entre as palavras, formando agrupamentos de palavras relacionadas (CAMARGO; JUSTO, 2018).

\section{A percepção de professoras cursistas do Parfor}

É pertinente informar que, para processar as informações de natureza lexical, o Iramuteq demanda uma quantidade mínima de palavras (CAMARGO; JUSTO, 2018). Essa quantidade de palavras foi obtida nas três primeiras questões, mas não nas duas últimas. Desse modo, nota-se que as professoras cursistas do Parfor que responderam às questões encontraram mais palavras para refletir sobre as próprias vivências formativas do que para realizar uma análise crítica sobre os pontos positivos e negativos da formação advinda do Parfor.

A primeira pergunta foi "Escreva sobre sua formação para ser professor/a antes de entrar no Parfor". A partir da análise de nuvem de palavras, constatou-se que os termos mais frequentes foram "Parfor" (12 vezes), "formação" (11 vezes) e "sala de aula" (nove vezes). Pela análise de similitude, percebeu-se que as respostas permearam um núcleo central, "Parfor", do qual se espalhavam dois elementos organizadores, a saber, "professor" e "formação". O agrupamento "formação" relacionou-se com outros dois agrupamentos, "ensino médio" e "sala de aula". Desse modo, tem-se que a formação parece relacionar-se mais com a ideia de sala de aula e do ensino médio do que com o agrupamento professor, que foi composto pelas palavras "conhecimento", "educação", "cursar" e "aluno". 
Essa compreensão faz sentido à medida que o Parfor tem como público-alvo professoras que estão na ativa e potencialmente buscam conhecimento para aprimorar a sua prática em sala de aula. Nesse sentido, destacam-se as respostas fornecidas pelas professoras:

[...] eu só tinha o ensino médio concluído [...]; foi uma oportunidade que o prefeito do município me deu. (A-1).

[...] não tinha nenhuma formação. (A-4).

[...] eu já tinha curso de Letras através do programa Fecop³. (A-5).

[...] participava apenas das formações do Paic ${ }^{4}$ ainda não tive nenhuma graduação. (S-3).

[...] a minha formação foi terminar o ensino médio em um curso pedagógico que durou dois anos [...]; fiquei só na sala de aula [...]. (S-6).

Esse conjunto de resultados indica a distância existente entre a formação inicial dessas professoras e as demandas formativas de uma sala de aula. Há um desequilíbrio entre as diferentes qualificações detectadas em diferentes docentes, conforme observado na fala das professoras A-5 e S-3. A formação inicial de um educador não diz tudo sobre ele, mas traz informações relevantes que devem ser consideradas ao se discutir sobre o que se espera dos programas educativos postos em prática pelas políticas públicas. O cenário de uma educação de qualidade não se sustenta com professoras de formação inicial inadequada, incompleta e sem apoio (LOUZANO et al., 2010; OLIVEIRA; ARAÚJO; DA SILVA, 2021). É necessária uma prática educativa que seja útil (MEZZAROBA; CARRIQUIRIBORDE, 2020), considerando as realidades sociais e, ao mesmo tempo, amparando teoricamente as análises reflexivas que permitam tecer uma compreensão sócio-histórica do contexto educacional, bem como da formação das professoras (PIMENTA, 2006; SILVA; CORRÊA, 2020; SOUSA; MARQUES, 2019).

A possibilidade de uma professora ser reflexiva e constituir uma epistemologia sobre a sua prática fica fragilizada quando faltam conhecimentos específicos que deveriam ser oriundos de uma formação inicial adequada e relacionada com a prática profissional. Uma reflexão sobre a prática exige a apropriação de um referencial teórico que possibilite à professora compreender o próprio pensamento e refletir sobre suas

3 Fundo Estadual de Combate à Pobreza (Fecop).

4 Programa Alfabetização na Idade Certa (Paic). 
ações, partindo de elementos epistemológicos constitutivos de uma teoria (LIBÂNEO, 2006). A formação anterior relatada pelas professoras cursistas do Parfor sinaliza a fragilidade formativa que dificulta perspectivas reflexivas, daí a importância de programas formativos que permitam adequar as formações dessas professoras para instigar o exercício crítico sobre a própria atuação pedagógica, tal como também foi observado nos estudos de Araújo et al. (2012), Mota (2015) e Rodrigues et al. (2018).

A segunda pergunta foi "Escreva sobre os motivos que lhe levaram a ser professora". A nuvem de palavras evidenciou que a palavra "professor" foi a que mais apareceu (17 vezes). Outros verbetes que se destacaram foram "criança" (sete vezes), "motivo" (seis vezes) e "oportunidade" (seis vezes). Em relação à motivação que as havia levado ao magistério, algumas respostas indicaram falta de opção, a exemplo:

\footnotetext{
Na minha cidade, o que era oferecido para as pessoas pobres era na classe de professores [...]; resolvi me satisfazer sendo professora simplesmente para adquirir o meu próprio sustento [...]. (S-1).
}

Os motivos que me levaram a ser professora: primeiro a necessidade de ter um trabalho [...]. (S-2).

De início, foi por ser a única proposta de trabalho. (S-4).

Outras professoras evidenciaram antigas motivações para docência, tais como:

Antes de iniciar as aulas no Parfor [...], participava mensalmente nas trocas de experiências com as demais profissionais na própria sala de aula [...]. Sempre gostei muito de crianças, me identificava com a sala de aula [...]. (A-3).

Antes de entrar no Parfor, eu já tinha cursado Letras através do programa Fecop [...]. Desde criança, quando entrei na escola, já despertou em mim o desejo de ser professora [...]. (A-5).

A minha formação vem desde o normal médio; cada ano de estudo eu já fazia estágio [...]. Só me aproximei da educação porque tinha estudado para ser professora [...]. (A-6).

As respostas de S-1, S-2 e S-4 indicam que o ingresso no magistério foi uma necessidade, e não uma escolha profissional. Ser professora seria uma questão de sobrevivência. Ao investigar as motivações para a docência como profissão, Silva e Corrêa (2020) e Sousa e Marques (2019) verificaram que muitas vezes o curso de Pedagogia era uma segunda opção, escolhida como uma oportunidade de terminar os estudos e/ou de melhorar as condições financeiras. Essa percepção também ecoou, durante as aulas, quando as cursistas do Parfor afirmaram que filho ou filha de rico,

Educ. Form., Fortaleza, v. 6, n. 3, e4646, set./dez. 2021

DOI: https://doi.org/10.25053/redufor.v6i2.4646

https://revistas.uece.br/index.php/redufor/index 
naqueles contextos, não se tornam professores(as). Já nas respostas de A-3, A-5 e A-6, havia um interesse pela profissão para além do sustento familiar e, aparentemente, faltavam oportunidades de acesso para essa formação, visto que as professoras buscavam se instrumentalizar conforme lhes era possível.

O princípio de que são as realidades e contextos sociais que configuram os projetos pessoais pode ser aplicado às duas realidades. Enquanto no primeiro contexto a escolha pela profissão está fortemente relacionada com a sobrevivência e a necessidade de um trabalho, no segundo contexto encontram-se motivos baseados nas formações iniciais que mobilizaram o desejo à docência. Esses dois contextos evidenciam que ser professora não tem respaldo no status social e que a formação de professores não é centralidade de uma política de Estado.

Faz-se necessário problematizar as condições objetivas de formação, de vida e de trabalho das professoras e ponderar até que ponto estas possibilitam a reflexividade. Como se não bastasse a formação docente precária no Brasil, marcada pela demanda de projetos emergenciais como o Parfor (BRASIL, 2009a, 2013, 2016a; SANTOS, 2018), Louzano et al. (2010) apontaram que faltam estudos empíricos que analisem a qualificação dos candidatos à carreira docente e que o ingresso no magistério tem critérios pouco comprometidos com a qualidade do profissional. No Brasil, o discurso sobre a formação docente e professoras reflexivas constitui mera temática dissociada das necessárias dimensões político-epistemológicas, sem nenhuma preocupação na elevação do estatuto da profissionalidade (PIMENTA, 2006).

A terceira pergunta foi "O Parfor está contribuindo com a sua formação? De que forma as aulas do Parfor mudam a sua atuação em sala de aula? Explique um pouco". A nuvem de palavras indicou que duas palavras foram mais frequentes, a saber: "aula" (21 vezes) e "Parfor" (17 vezes). Por meio da análise de similitude, verificou-se que cada um desses verbetes compôs um agrupamento. O agrupamento do verbete "aula" foi composto pelas palavras "formação", "sala", "professor", "prática" e "criança", enquanto o agrupamento "Parfor" foi integrado pelas palavras "estar", "conhecimento", "contribuir" e "adquirir".

Ao analisar os dois agrupamentos, é possível inferir que, por um lado, o Parfor permite que as professoras cursistas adquiram o conhecimento necessário e, por outro 
lado, estaria mais associado à prática da sala de aula. As participantes afirmaram o seguinte:

Sim, depois que entrei no Parfor, tenho mudado a maneira de trabalhar com as crianças. (S-5).

O Parfor só tem a contribuir com a formação dos professores por ser um curso direcionado exclusivamente a preparar os professores para atuar em sala. (A-2).

[...] o Parfor me abriu novos horizontes, me possibilitou o acesso ao conhecimento das ciências, das técnicas, dos métodos [...]. (S-7).

A fala das professoras reforça a ideia de que a sala de aula se constitui como seu campo de saber. Sobre isso, Oliveira, Araújo e Da Silva (2021, p. 14) "[...] apontam que o fazer diário de seu ofício constitui lócus de formação muito mais eficiente, revelando o caráter formador da prática docente". Os programas voltados para formação de professoras em exercício são importantes, pois permitem que as professoras tenham oportunidade de refletir sobre as suas práticas e adquirir suportes que não possuíam, bem como a possibilidade de compartilhar e valorizar saberes e experiências com pares que estão em situação laboral semelhante (DUARTE, 2019). Teorizar sobre as próprias práticas implica considerar a complexidade dos processos de ensinar e aprender, contemplando a escola como espaço de produção de conhecimento. Entretanto, esse espaço só encontra fertilidade quando se permite o desenvolvimento profissional das professoras direcionado à reflexão, à inovação, ao diferente e ao colaborativo entre diferentes coletivos (LIBÂNEO, 2006; PIMENTA, 2006).

Essas oportunidades são importantes, visto que as transformações nas suas práticas ocorrem na medida em que as professoras ampliam a consciência sobre a própria prática (PIMENTA, 2006). Como sugeriu Pimenta (2006, p. 26), “[...] a teoria como cultura objetivada é importante na formação docente, uma vez que, além de seu poder formativo, dota os sujeitos de pontos de vista variados para uma ação contextualizada". Assim, refletir na e sobre a ação é um exercício que precisa ser viabilizado em toda formação inicial docente (LIMA; ANDRADE; COSTA, 2020; MEZZAROBA; CARRIQUIRIBORDE, 2020), contemplando-se, desse modo, também as professoras cursistas do Parfor (SCHUETZ, 2018).

A questão quatro era para destacar os pontos positivos e negativos sobre 0 Parfor. Devido à pouca quantidade textual, não foi possível realizar as análises pelo 
Iramuteq. Entre os pontos positivos, foram mencionadas a qualidade das disciplinas e professores e a possibilidade de melhorar a prática pedagógica. Alguns aspectos negativos indicados foram o cansaço, a dificuldade de deslocamento e a falta de acesso à biblioteca.

A questão cinco era para fazer observações, indicações ou sugestões, à qual muitas professoras não responderam. Dentre as respostas dessas questões, tem-se:

\section{[...] os professores são atenciosos, compromissados e competentes. (S-3). \\ O Parfor veio para melhorar nós, professores [...]; ajuda a perceber nossas ações e incentiva a fazer diferente. (S-5).}

Dá oportunidade aos professores que ainda não têm uma graduação. (A-2).

\section{[...] uma ótima oportunidade para a minha formação. (A-4).}

Além das respostas ao questionário, durante os encontros as professoras cursistas do Parfor relataram a sobrecarga de atividades no trabalho e o deslocamento como principais entraves para um aproveitamento adequado da formação. Elas atuavam como professoras de segunda a sexta-feira em tempo integral e, no meio da tarde de sexta-feira, deixavam a área rural com destino à área urbana, onde assistiriam às aulas do curso. Na própria sexta-feira, elas retornavam para suas casas, chegando tarde da noite. No sábado, habitualmente, acordavam de madrugada para cuidar dos afazeres comuns das suas casas antes de irem às aulas de sábado.

Como indicou Carvalho (2020), o Parfor consegue chegar aos lugares em que professoras das escolas mais distantes estão. E, como se não bastasse, esses entraves de falta de tempo e de dificuldade de locomoção se somam às burocracias estabelecidas pelas prefeituras e escolas para liberar seus funcionários para eventos formativos, conforme relatado por Santos (2018). Nesse sentido, vale recordar a defesa de Louzano et al. (2010) de que, para atrair pessoas mais qualificadas para a carreira docente, seria preciso melhorar os incentivos salariais e o status social da profissão.

As professoras cursistas do Parfor da Urca estão inseridas em contextos sociais específicos, marcados pela distância geográfica das áreas urbanas e desvalorização da profissão. As contradições de suas realidades são fatores importantes de serem considerados para a construção de posturas reflexivas (MEZZAROBA; CARRIQUIRIBORDE, 2020). É preciso integrar a teoria e a prática de modo que as 
professoras "[...] compreendam os contextos históricos, sociais, culturais, organizacionais e de si próprias como professoras" (PIMENTA, 2006, p. 24).

A formação e a docência são complexas, portanto é preciso atentar-se para não oferecer uma formação meramente transmissora, com pouca inovação, de forma descontextualizada e que motiva as professoras em um dado momento e as abandona logo ali na frente (IMBERNÓN, 2009). Nota-se que a formação ofertada por meio do Parfor pode ser considerada um primeiro passo para minimizar os impactos da falta de uma formação inicial qualificada. Entretanto, ao se pensar na proposta de professoras reflexivas e de uma atuação pautada na epistemologia da prática, faz-se necessária a busca por novas fontes de conhecimento profissional e de um acompanhamento permanente. Para se aproximar da epistemologia da prática e dela extrair conhecimentos adequados às suas práticas, a formação deve constituir-se coletiva e permanentemente. No coletivo, a crítica conjunta deve ser feita para além do contexto da sala de aula, incluindo os espaços sociais como condicionantes da docência (PIMENTA, 2006). De forma permanente, para romper com a linearidade cultural, promovendo o diálogo com os contextos e diversidades (IMBÉRNON, 2009).

\section{Considerações finais}

O Parfor é um programa importante para a qualificação docente, especialmente quando se percebe que existem realidades profissionais distintas, por vezes marcadas por um processo histórico de desvalorização dos processos educacionais como um todo. Dessa forma, no presente trabalho fez-se uma análise crítica sobre a professora reflexiva a partir da percepção de docentes cursistas de Pedagogia do Parfor da Urca, no interior do Ceará.

As professoras que refletiram nas e sobre as ações pedagógicas indicaram a distância entre a formação inicial e as demandas formativas da sala de aula, elencaram motivações distintas para ingressar na docência, como a sobrevivência e interesse pela atuação, e apontaram que a formação do Parfor foi necessária e importante para auxiliá-las a ter uma prática mais reflexiva. Permitir aos professores discutir sobre as difíceis realidades profissionais e de sobrevivência contempla novos

Educ. Form., Fortaleza, v. 6, n. 3, e4646, set./dez. 2021 
olhares e outros pensamentos sobre possibilidades de reflexão e aproximação da epistemologia da prática.

Indica-se como limitação o fato de o estudo ter emergido de uma atividade prática de sala de aula em que não foi possível que alunos de outras turmas e regiões respondessem ao questionário para ter um panorama mais amplo da percepção dos alunos sobre o Parfor, o que pode ser feito em estudos futuros, para realizar comparações e identificar similaridades e diferenças. Por fim, acredita-se que este trabalho foi importante para dar voz a essas professoras cursistas do Parfor, que vivem numa área rural no interior de um estado marcado pela pobreza e desigualdade social.

\section{Referências}

ARAÚJO, C. R. P. et al. Análise crítica do Parfor enquanto propósito e realidade no Cariri Cearense. In: ENDIPE, 16, 2012, Campinas. Anais [...]. Campinas: Endipe, 2012.

BRASIL. Decreto no 6.755, de 29 de janeiro de 2009. Institui a Política Nacional de Formação de Profissionais do Magistério da Educação Básica, disciplina a atuação da Coordenação de Aperfeiçoamento de Pessoal de Nível Superior - Capes no fomento a programas de formação inicial e continuada, e dá outras providências. Diário Oficial [da] República Federativa do Brasil, Poder Executivo, Brasília, DF, 30 jan. 2009a.

BRASIL. Decreto no 8.752, de 9 de maio de 2016. Dispõe sobre a Política Nacional de Formação dos Profissionais da Educação Básica, considerando as Metas 15-16 do PNE (2014-2024). Diário Oficial [da] República Federativa do Brasil, Poder Executivo, Brasília, DF, 10 maio 2016a.

BRASIL. Lei o 4.024, de 20 de dezembro de 1961. Fixa as Diretrizes e as Bases para o Ensino de $1^{\circ}$ e $2^{\circ}$ graus, e dá outras providências. Diário Oficial [da] República Federativa do Brasil, Poder Executivo, Brasília, DF, 27 dez. 1961.

BRASIL. Lei no 5.692, de 11 de agosto de 1971. Fixa Diretrizes e Bases para o Ensino de $1^{\circ}$ e $2^{\circ}$ Graus, e dá outras providências. Diário Oficial [da] República Federativa do Brasil, Poder Executivo, Brasília, DF, 12 ago. 1971.

BRASIL. Lei no 9.394, de 20 de dezembro de 1996. Estabelece as Diretrizes e Bases da Educação Nacional. Diário Oficial [da] República Federativa do Brasil, Poder Executivo, Brasília, DF, 21 dez. 1996.

BRASIL. Plano Nacional de Formação de Professores da Educação Básica - Parfor. Brasília, DF: Capes, 2010. 
BRASIL. Portaria Normativa no 9, de 30 de junho de 2009. Institui o Plano Nacional de Formação dos Professores da Educação Básica no âmbito do Ministério da Educação. Diário Oficial [da] República Federativa do Brasil, Poder Executivo, Brasília, DF, 10 jun. 2009b.

BRASIL. Relatório de gestão 2009-2013 da Diretoria de formação de professores da educação básica - DEB. Brasília, DF: Capes, 2013.

BRASIL. Resolução no 510, de 7 de abril de 2016. Dispõe sobre as normas aplicáveis a pesquisas em Ciências Humanas e Sociais cujos procedimentos metodológicos envolvam a utilização de dados diretamente obtidos com os participantes ou de informações identificáveis ou que possam acarretar riscos maiores do que os existentes na vida cotidiana, na forma definida nesta Resolução. Diário Oficial [da] República Federativa do Brasil, Poder Executivo, Brasília, DF, 8 abr. 2016b.

CAMARGO, B. V.; JUSTO, A. M. Tutorial para uso do software Iramuteq. Florianópolis: Universidade Federal de Santa Catarina, 2018.

CARVALHO, M. C. A. Uma década de formação de professores pelo Parfor: desafios, lições e perspectivas na conjuntura atual. Revista Formação em Movimento, Seropédica, v. 2, n. 4, p. 459-476, 2020.

DUARTE, M. R. Memórias e vivências formativas das educadoras do Parfor. In: RODRIGUES, B. et al. (org.). Memórias e vivências docentes: histórias e práticas de alunos(as) do Parfor. Belém: Paka-Tatu, 2019. p. 11-21.

IMBERNÓN, F. Formação permanente do professorado: novas tendências. São Paulo: Cortez, 2009.

LIBÂNEO, J. C. Reflexividade e formação de professores: outra oscilação do pensamento pedagógico brasileiro. In: PIMENTA, S. G.; GHEDIN, E. (org.). Professor reflexivo no Brasil: gênese e crítica de um conceito. 4. ed. São Paulo: Cortez, 2006. p. 53-79.

LIMA, I. S.; ANDRADE, A.; COSTA, N. M. A prática pedagógica na formação inicial de professores em Cabo Verde: perspectivas dos supervisores. Educação \& Formação, Fortaleza, v. 5, n. 13, p. 3-26, 2020.

LIMA, M. S. L.; GOMES, M. O. Redimensionando o papel dos profissionais da Educação: algumas considerações. In: PIMENTA, S. G.; GHEDIN, E. (org.). Professor reflexivo no Brasil: gênese e crítica de um conceito. 4. ed. São Paulo: Cortez, 2006. p. 163-186.

LOUZANO, P. et al. Quem quer ser professor? Atratividade, seleção e formação docente no Brasil. Estudos em Avaliação Educacional, São Paulo, v. 21, n. 47, p. 543-568, 2010. 
MEZZAROBA, C.; CARRIQUIRIBORDE, N. Teoría y práctica - Cuestiones imprescindibles a la práctica educativa. Educação \& Formação, Fortaleza, v. 5, n. 15, p. e2807, 2020.

MOTA, M. É. B. O habitus acadêmico: o curso de Pedagogia do Parfor - Urca e sua influência na ação docente dos alunos-professores. 2015. Tese (Doutorado em Educação) - Programa Pós-Graduação em Educação, Universidade Federal do Ceará, Fortaleza, 2015.

OLIVEIRA, S. M. S.; ARAÚJO, F. M. L.; DA SILVA, C. D. M. A Prática como lócus de produção de saberes: vozes de professores sobre formação inicial e práticas escolares cotidianas. Educação \& Formação, Fortaleza, v. 6, n. 1, p. e2885, 2021.

PIMENTA, S. G. Professor reflexivo: construindo uma crítica. In: PIMENTA, S. G.; GHEDIN, E. (org.). Professor reflexivo no Brasil: gênese e crítica de um conceito. 4. ed. São Paulo: Cortez, 2006. p. 17-52.

RODRIGUES, D. F. et al. O plano nacional de formação de professores da educação básica - Parfor da Universidade Regional do Cariri - Urca sob a lente dos egressos (Crato-CE, 2010-2015). Revista Internacional de Formação de Professores, Itapetininga, v. 3, n. 2, p. 342-361, 2018.

SANTOS, L. Análise do Parfor no curso de Pedagogia da UFRRJ à luz das reformas educacionais. Revista de Políticas Públicas, São Luís, v. 22, n. esp., p. 1509-1526, 2018.

SCHUETZ, P. P. Subjetividades docentes tecidas a partir de formações e reverberadas às práticas escolares. 2018. Dissertação (Mestrado em Educação) - Programa de Pós-Graduação em Educação, Universidade Estadual do Ceará, Fortaleza, 2018.

SILVA, K.; CORRÊA, C. P. Atratividade docente entre os ingressantes no curso de Pedagogia. Educação \& Formação, Fortaleza, v. 5, n. 13, p. 59-78, 2020.

SOUSA, E.; MARQUES, E. O processo de constituir-se professor na relação objetividade-subjetividade: significações acerca da mediação social na escolha pela docência. Educação \& Formação, Fortaleza, v. 4, n. 11, p. 82-96, 2019.

TARDIF, M. Saberes docentes e formação profissional. 6. ed. Petrópolis: Vozes, 2002.

\footnotetext{
Paulo Pedro Schuetz, Universidade Regional do Cariri, Departamento de Educação

i-https://orcid.org/0000-0003-2676-1441

Mestre em Educação pela Universidade Estadual do Ceará (UECE), Fortaleza. Professora do Departamento de Educação da Universidade Regional do Cariri.

Contribuição de autoria: Administração do projeto, análise formal, conceituação, curadoria de dados, escrita - primeira redação, escrita - revisão e edição, investigação, metodologia, obtenção de financiamento, recursos, validação e visualização.

Lattes: http://lattes.cnpq.br/7367002415045257

E-mail: paulo.2004.2@gmail.com
} 
Gabriel Vitor Acioly Gomes, Universidade São Francisco, Laboratório de Estudos e Práticas em Avaliação Psicológica ii(Dhttps://orcid.org/0000-0001-6565-3094

Mestre em Educação pela Universidade Estadual do Ceará (UECE), doutorando do Programa de Pós- Graduação em Psicologia da Universidade São Francisco (USF) - Campinas, Laboratório de Estudos e Práticas em Avaliação Psicológica (Leapsi) da UECE.

Contribuição de autoria: Análise formal, conceituação, curadoria de dados, escrita - primeira redação, escrita - revisão e edição, metodologia, obtenção de financiamento, recursos, software, validação e visualização.

Lattes: http://lattes.cnpq.br/2960342069334069

E-mail: gabrigom93@hotmail.com

Lucila Moraes Cardoso, Universidade Estadual do Ceará, Programa de Pós-Graduação em
Educação
iii (@https://orcid.org/0000-0002-8890-9352
Doutora em Psicologia pela Universidade Estadual do Ceará (UECE), Fortaleza, professora do
Programa de Pós-Graduação em Educação da UECE e colaboradora no Programa de Pós-
Graduação em Psicologia da Universidade Federal do Ceará (UFC), Laboratório de Estudos e
Práticas em Avaliação Psicológica (Leapsi) da UECE.
Contribuição de autoria: Administração do projeto, análise formal, conceituação, curadoria de dados,
escrita - primeira redação, escrita - revisão e edição, metodologia, obtenção de financiamento,
recursos, supervisão, validação e visualização.
Lattes: http://lattes.cnpq.br/8664062189071507
E-mail: lucila.cardoso@uece.br

Editora responsável: Lia Machado Fiuza Fialho Pareceristas ad hoc: Luciana Mendes e Karla Vasconcelos

\section{Como citar este artigo (ABNT):}

SCHUETZ, Paulo Pedro; GOMES, Gabriel Vitor Acioly; CARDOSO, Lucila Moraes. A percepção de professoras cursistas do Parfor sobre as contribuições do Parfor à prática pedagógica. Educ. Form., Fortaleza, v. 6, n. 3, e4646, 2021. Disponível em:

https://revistas.uece.br/index.php/redufor/article/view/4646

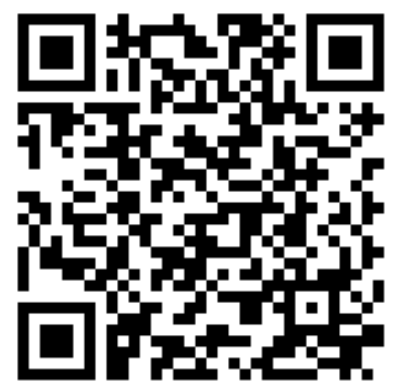

Recebido em 18 de janeiro de 2021.

Aceito em 24 de abril de 2021.

Publicado em 28 de junho de 2021.

Educ. Form., Fortaleza, v. 6, n. 3, e4646, set./dez. 2021

DOI: https://doi.org/10.25053/redufor.v6i2.4646

https://revistas.uece.br/index.php/redufor/index 